ORIGINAL ARTICLE

\title{
Mucin expression in pleomorphic adenoma of salivary gland: a potential role for MUC1 as a marker to predict recurrence
}

\author{
T Hamada, S Matsukita, M Goto, S Kitajima, S K Batra, T Irimura, K Sueyoshi, K Sugihara, \\ $S$ Yonezawa
}

J Clin Pathol 2004;57:813-821. doi: 10.1136/jcp.2003.014043

\begin{abstract}
See end of article for authors' affiliations

......................

Correspondence to: Dr S Yonezawa, Department of Human Pathology, Field of Oncology, Kagoshima University Graduate School of Medical and Dental Sciences, 8-35-1 Sakuragaoka, Kagoshima 890-8544, Japan; syoneza@m2.kufm. kagoshima-u.ac.jp

Accepted for publication 27 November 2003
\end{abstract}

\begin{abstract}
Background: Pleomorphic adenoma of the salivary gland (PA) is essentially a benign neoplasm. However, patients with recurrent PA are difficult to manage. There are rare reports on useful immunohistochemical markers to detect a high risk of recurrence when the primary lesions are resected.

Aims: To find a new marker to predict the recurrence of PA.

Methods: Primary lesions of PA were collected from nine patients showing subsequent recurrence and from 40 patients without recurrence during at least 10 years of follow up of the disease. Paraffin wax embedded tumour samples of the two groups were examined for the expression profiles of $\mathrm{MUC1}$ (differentially glycosylated forms), MUC2, MUC4, MUC5AC, and MUC6 using immunohistochemistry. Several clinicopathological factors were also examined.

Results: In univariate analysis of the factors examined, MUC1/DF3 high expression (more than $30 \%$ of the neoplastic cells stained) in the primary lesions was seen more frequently in patients with recurrence (four of nine) than in those without recurrence (three of $40 ; p=0.011$ ). Larger tumour size (more than $3.0 \mathrm{~cm}$ ) of the primary PA was also a significant $(p=0.035)$ risk factor for the recurrence of PA. In multivariate analysis, only high expression of MUC1/DF3 was found to be a significant independent risk factor for the recurrence of PA $(p=0.021)$.

Conclusions: Expression of MUC1/DF3 in PA is a useful marker to predict its recurrence. Those patients with PA showing positive MUC1/DF3 expression should be followed up carefully.
\end{abstract}

$\mathrm{P}$ eomorphic adenoma (PA) is the most common tumour of the salivary gland. Although this tumour is originally benign, the rate of recurrence is relatively high (2.5$32.5 \%) .{ }^{1-5}$ The frequency of recurrence is lower in most modern surgical series, although once recurrence occurs PA may have a high rate of re-recurrence. ${ }^{6}$ Recurrent PAs are often multinodular and frequently lack surrounding capsule, so that patients with recurrent PA of the salivary gland are difficult to manage. ${ }^{58}$ The prediction and prevention of recurrence are important for the treatment of PA.

An increased risk of local recurrence after primary surgery for PA has been suggested to be associated with the occurrence of pseudopodia, ${ }^{2}$ younger age of the patient, ${ }^{9-11}$ the stroma rich variant, ${ }^{11}$ and incomplete surgical excision. ${ }^{89}$ Incomplete surgical excision is believed to be the most essential factor, although in our experience, a few patients with PA treated by curative resection showed subsequent recurrence, and some with PA carrying residual tumours showed no recurrence (unpublished data; 26 cases in our files). Recently, it has also been reported that the stroma rich variant, ${ }^{12}$ intraoperative tumour spill, ${ }^{1212}{ }^{13}$ and inadequate resection ${ }^{4}$ may not be associated with an increased risk of recurrence. Consequently, the mechanism of PA recurrence is unclear. Although some recent immunohistochemical studies have revealed the intrinsic biological characters of this tumour, such as cell proliferation activity and overexpression of the progesterone receptor, the oestrogen receptor, and p53, ${ }^{14-16}$ there were few useful markers that enabled us to predict subsequent recurrence at the point of initial surgery of PA.

Mucins are high molecular weight glycoproteins with oligosaccharides attached to serine or threonine residues of the mucin core protein backbone by $O$-glycosidic linkages.
During the past few years, core proteins for human mucins (MUC1-9, MUC11-13, and MUC15-17) have been identified and named chronologically. ${ }^{17}{ }^{18}$ Of the mucins identified, MUCl is a membrane bound mucin detected in most epithelial tissues. ${ }^{17}$ MUC2 is an intestinal-type secretory mucin and is expressed mainly in goblet cells of the intestine. ${ }^{19}$ MUC4 was first reported as tracheobronchial mucin ${ }^{20}$ and is a membrane mucin. ${ }^{21}$ Similar to MUC2, MUC5AC and MUC6 are secretory mucins and are expressed mainly in the gastric surface mucous cells and pyloric glands, respectively. ${ }^{22}$

\section{"Recurrent pleomorphic adenomas are often multinodular and frequently lack surrounding capsule, so that patients with recurrent PA of the salivary gland are difficult to manage"}

Our immunohistochemical studies for mucin expression in various human tumours have shown that the expression of MUCl mucin is associated with invasive growth of the tumours and poor outcome of the patients, whereas the expression of MUC2 mucin is associated with non-invasive growth of the tumours and a favourable outcome of the patients. ${ }^{23-29}$ MUC4 has already been identified in normal salivary glands, ${ }^{30}$ and has been reported to be expressed in pancreatic adenocarcinoma. ${ }^{31}$ We also recently reported that MUC5AC was highly expressed in both aggressive and indolent tumours of the pancreas (invasive ductal carcinoma

Abbreviations: $A B C$, avidin-biotin complex; $\mathrm{Cl}$, confidence interval; MAb, monoclonal antibody; PA, pleomorphic adenoma; PBS, phosphate buffered saline; OR, odds ratio 
and intraductal papillary mucinous neoplasm of the pancreas), ${ }^{32}$ and that MUC2 and MUC6 were highly expressed in mucinous carcinoma of the breast with less aggressive biological behaviour. ${ }^{33}$ Thus, it is of interest to investigate the relation between the expression of these mucins and recurrence in PA.

In our present study, to find a useful marker to predict the recurrence of $\mathrm{PA}$, we examined the expression profiles of different glycoforms of MUC1 mucins using five monoclonal antibodies (MAbs) of differing carbohydrate specificities (NCL-MUC-1-CORE, DF3, MY.1E12, NCL-MUC-1, and HMFG-1), in addition to antibodies to MUC2, MUC4, MUC5AC, and MUC6 in the primary lesions of PA; we compared these expression profiles between a group of patients in whom post-surgical recurrence occurred and a group in whom no recurrence was seen using immunohistochemistry. Basic clinicopathological factors were also compared between the two groups.

\section{MATERIALS AND METHODS Tissue samples}

Primary lesions from nine patients with PA (parotid gland, seven; submandibular gland, one; palate, one) showing subsequent recurrence (designated as "recurrence group") were retrieved from the files of the first department of oral and maxillofacial surgery, Kagoshima University dental school, and department of pathology, Kagoshima City Hospital, Kagoshima, Japan. Twenty three patients who had recurrent PA lesions were found in our files, but the primary lesion specimens were available in only nine. The average interval between resection of the primary lesion and the initial recurrence was 6.4 years (range, 3-11) in the nine patients. The rate of re-recurrence was $22 \%$ (two of nine) in the recurrence group. For comparison, primary lesions from 40 patients with PA (parotid gland, 17; submandibular gland, seven; palate, 13; other oral mucosa, three) showing no recurrence during at least 10 years of follow up (designated as "non-recurrence group") were retrieved from the same files. The primary lesions showing subsequent recurrence were resected between 1975 and 1994. The primary lesions showing no recurrence were resected between 1985 and 1992. Our study was ethically approved by the Kagoshima University Faculty of Medicine human investigation committee.

All the specimens were fixed in 10\% formalin, embedded in paraffin wax, and cut into $4 \mu \mathrm{m}$ thick serial sections for immunohistochemistry, in addition to the usual haematoxylin and eosin staining.

\section{Immunohistochemistry Antibodies}

Table 1 details the antibodies used for immunohistochemistry. For MUCl expression, different glycoforms of MUCl were examined by five MAbs, namely: NCL-MUC-1CORE, DF3, MY.1E12, NCL-MUC-1, and HMFG-1. NCLMUC-1-CORE recognises MUCl mucin core peptide (GVTSAPDTRPAP) $^{34}$ (clone Ma552; Novocastra Laboratories Ltd, Newcastle, UK). DF3 identifies MUCl core peptide (APDTRPAP).$^{34}$ Although the binding of DF3 to protein has been reported to be enhanced by the presence of carbohydrates, ${ }^{35}$ a recent study found that DF3 does not recognise a carbohydrate containing epitope. ${ }^{34}$ MY.1E12 is specific for sialylated MUC1 mucin. ${ }^{36}$ NCL-MUC-1 recognises a carbohydrate epitope of MUCl (exact epitope unknown) ${ }^{37}$ (clone Ma695; Novocastra Laboratories). The binding of HMFG-1 (kindly provided by Dr J Taylor-Papadimitriou, Imperial Cancer Research Fund Laboratories, London, UK) to core protein epitopes (APDTR) ${ }^{34}$ is influenced by the carbohydrate chains and by sialic acid, although it detects fully glycosylated MUCl mucin. ${ }^{38}$ For simple representation,
Table 1 Monoclonal antibodies used

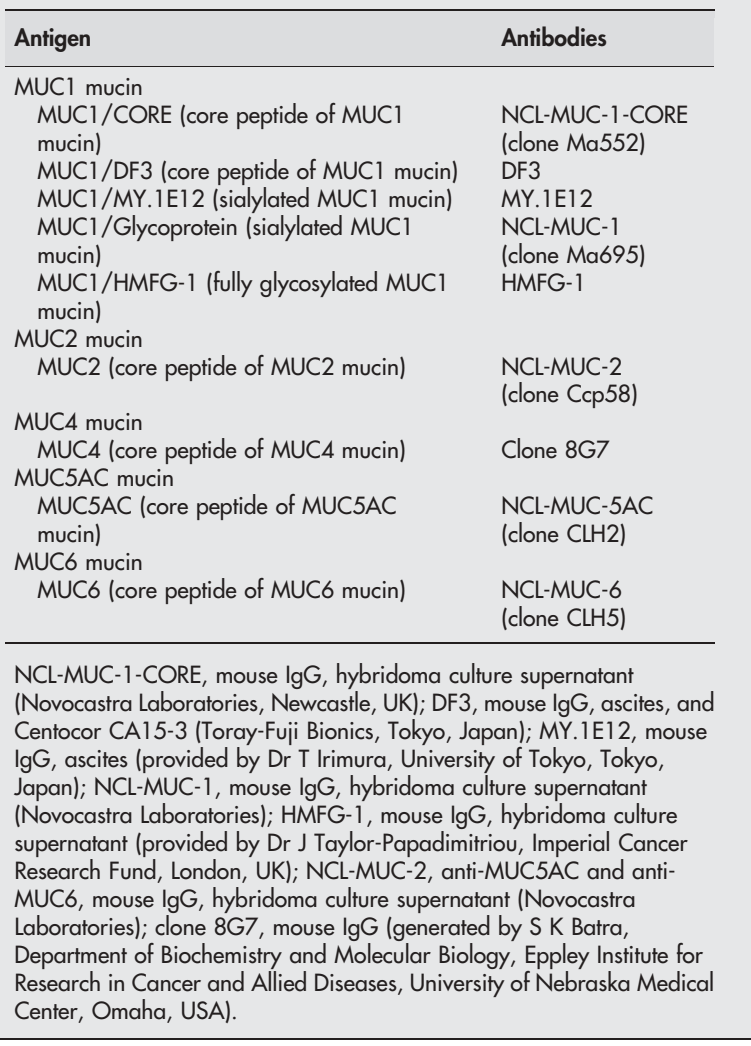

"MUC1/CORE, MUC1/DF3, MUC1/MY.1E12, MUCl/glycoprotein, and MUCl/HMFG-l" were used for the MUCl mucin antigens detected by MAbs NCL-MUC-1-CORE, DF3, MY.1E12, NCL-MUC-1, and HMFG-1, respectively.

MUC2 was detected by MAb NCL-MUC-2 (clone Ccp58; Novocastra Laboratories). MUC4 was detected by mouse MAb clone 8G7.31 ${ }^{39}$ MUC5AC and MUC6 were detected by MAb NCL-MUC-5AC (clone CLH2) and MAb NCL-MUC-6 (clone CLH5), respectively (Novocastra Laboratories).

Biotinylated, affinity purified horse antimouse IgG and avidin-biotinylated horseradish peroxidase $(\mathrm{ABC})$ complex were purchased from Vector Laboratories (Burlingame, California, USA) as the Vectastain Elite ABC kit.

\section{Staining procedure}

Immunohistochemical staining were carried out using an immunoperoxidase method and the $\mathrm{ABC}$ complex as described previously. ${ }^{25-27}{ }^{33}$ Briefly, each section was dewaxed with xylene. Endogenous peroxidase was blocked by incubating the sections in $0.3 \%$ hydrogen peroxide in absolute methanol at room temperature for 30 minutes. After hydration in decreasing concentrations of ethanol in water, the sections were washed in $10 \mathrm{mM}$ phosphate buffered saline (PBS), pH 7.4. Next, 2\% horse serum in PBS was applied for 30 minutes at room temperature to prevent non-specific staining. The sections were incubated with dilutions of the primary antibodies (NCL-MUC-1-CORE, 1/100; DF3, 1/10; MY.1E12, 1/200; NCL-MUC-1, 1/100; HMFG-1, 1/100; NCLMUC-2, 1/600; clone 8G7, 1/3000; NCL-MUC-5AC, 1/100; and NCL-MUC-6, 1/100) in PBS with $1 \%$ bovine serum albumin for 16 hours at $4^{\circ} \mathrm{C}$. The sections were washed three times with PBS, incubated with the biotinylated secondary antibody, and then washed three times with PBS. All the sections were then incubated with the $\mathrm{ABC}$ complex for 30 minutes. After washing with PBS three times, the sections were finally 


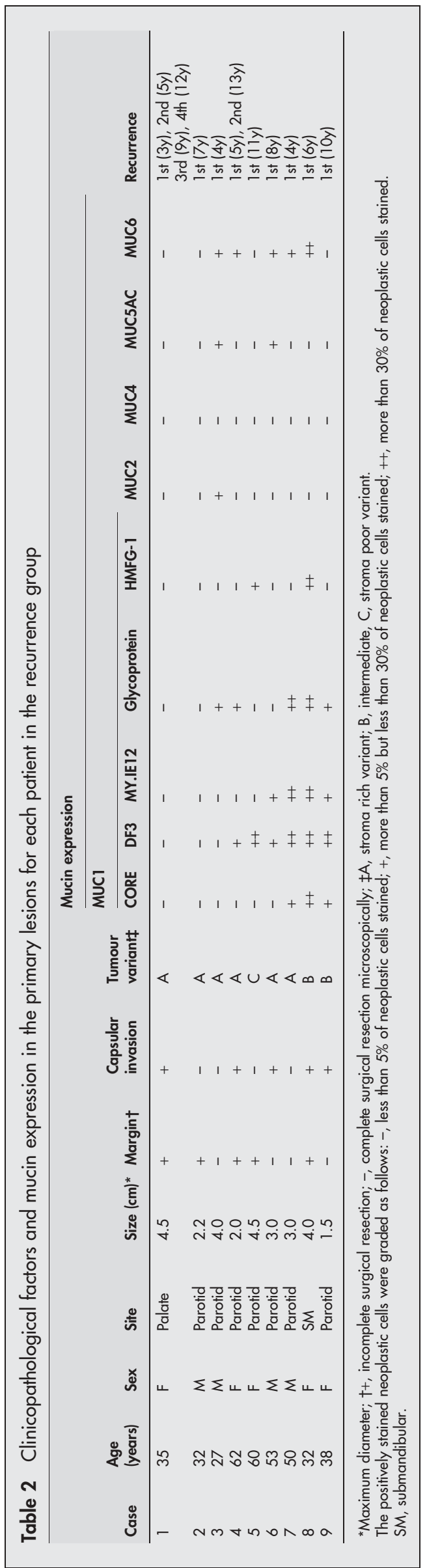

reacted with diaminobenzidine substrate for 10 minutes for visualisation, rinsed with tap water, counterstained with haematoxylin, and mounted. Reaction products were not present when non-immune serum or PBS was used instead of the primary antibodies.

\section{Evaluation of the results by scoring}

The percentages of positively stained neoplastic cells were graded as follows: -, less than $5 \%$ of neoplastic cells stained; + , more than $5 \%$ but less than $30 \%$ of neoplastic cells stained; ++ , more than $30 \%$ of neoplastic cells stained. In addition, for statistical analysis, the cases were divided into two groups: the low expression group, composed of the - and + cases (less than $30 \%$ of neoplastic cells stained), and the high expression group, composed of the ++ cases (more than 30\% of the neoplastic cells stained).

\section{Statistical analysis}

Both the clinicopathological factors and the ratio of the numbers of patients classified into the high and low expression groups for each mucin were compared between the recurrence group and non-recurrence group, with significant $(p<0.05)$ differences determined by the $\chi^{2}$ test or Fisher's exact test. Univariate logistic regression analysis was then conducted to evaluate the risk on the association of recurrence as estimated by the odds ratio (OR) and 95\% confidence intervals ( $95 \% \mathrm{CI}$ ). For the multivariate model, to evaluate the independent risk factors on the association of recurrence, we used 0.20 as the cutoff $p$ value to select the analysed factors from the univariate analysis data. Because preliminary analysis showed relative risks for recurrence associated with patient's age younger than 35 years and with tumour size larger than $3.0 \mathrm{~cm}$, those categories were grouped and served as the reference for the age variant and for the size variant. A probability of $\mathrm{p}<0.05$ was considered significant.

\section{RESULTS}

Table 2 summarises the clinicopathological features and mucin expression profiles in the primary lesions of the nine patients in the recurrence group. Table 3 summarises these data in the 40 patients in the non-recurrence group.

\section{Expression of mucins in normal salivary glands}

In normal salivary glands (fig $\mathrm{lA}-\mathrm{F}$ ), low expression of all MUCl isotypes was seen at the surface of the ductal cells but not in the acinar cells (MUC1/DF3; fig 1B). MUC2, MUC4, MUC5AC, and MUC6 were expressed in the epithelium of intralobular ducts, but were not expressed in the acinar cells (fig 1C-F). MUC4 expression in the normal ducts was relatively intense (fig $1 \mathrm{D}$ ).

\section{Expression of mucins in primary lesions of PA}

All types of MUC1 and MUC6 were expressed in the primary lesions of several PAs (tables 2 and 3 ). In the recurrence group, the numbers of patients classified into the high expression group were as follows: MUC1/CORE, one of nine; MUC1/DF3, four of nine; MUC1/MY.1E12, two of nine; MUCl/glycoprotein, two of nine; MUCl/HMFG-1, one of nine; and MUC6, one of nine (table 2). In the non-recurrence group, the numbers of patients classified into the high expression group were as follows: MUC1/CORE, five of 40; MUCl/DF3, three of 40; MUC1/MY.1E12, six of 40; MUCl/ glycoprotein, six of 40; MUCl/HMFG-1, none of 40; and MUC6, four of 40 (table 3 ).

In contrast, MUC2, MUC4, and MUC5AC showed no expression in most cases, but weakly positive expression in a few cases (tables 2 and 3 ). No patients were classified into the high expression group for MUC2, MUC4, and MUC5AC 


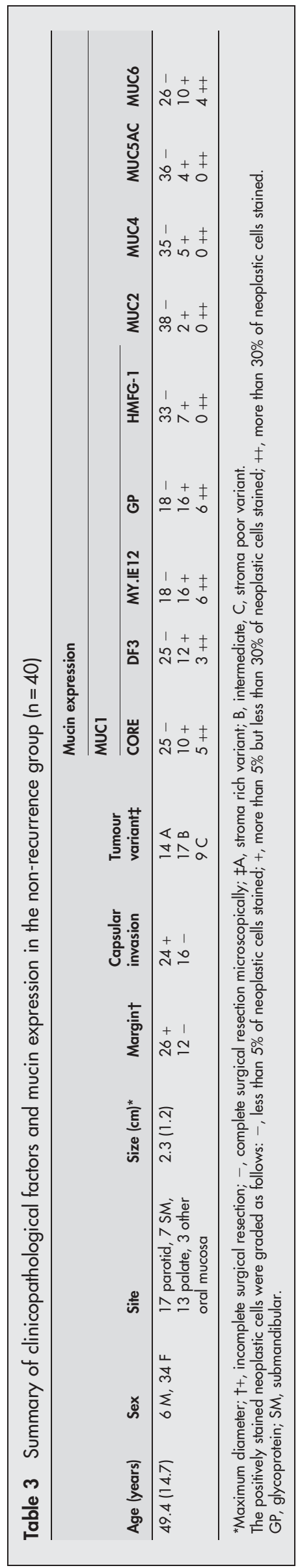

in both the recurrence and non-recurrence groups (tables 2 and 3 ).

There was no significant relation between the expression of each mucin and the following clinicopathological factors: age, size, sex, site, capsular invasion, tumour variant, and positive surgical margin ( $\chi^{2}$ test or Fisher's exact test, data not shown).

In the neoplastic cells, all MUCl antigens were expressed at the cell membrane and/or cytoplasm of the epithelial/ myoepithelial components, and MUC6 was expressed in the cytoplasm. MUCl expression was occasionally seen in the capsular invasion areas in the patients with high expression of MUCl (fig 2).

\section{Univariate analysis of clinicopathological features and mucin expression}

Using Fisher's exact test, in the primary lesions of the recurrence group, larger tumour size (more than $3.0 \mathrm{~cm}$ ) ( six of nine) and high expression of MUC1/DF3 (four of nine) were significantly more frequent than in the primary lesions of the non-recurrence group ( 11 of 40 and three of 40; $\mathrm{p}=0.016$ and $\mathrm{p}=0.048$, respectively) (tables 4 and 5).

Table 4 summarises the univariate regression analysis of clinicopathological features. The larger tumour size of primary PAs was a significant risk factor affecting the recurrence of PA $(\mathrm{p}=0.035$; OR $=5.27 ; 95 \% \mathrm{CI}, 1.12$ to 24.85; table 4). Other clinicopathological factors such as capsular invasion and stromal ratio of the tumours showed no significant risk.

Table 5 summarises the univariate regression analysis of mucin expression. High expression of MUCl/DF3 was a significant risk factor for the recurrence of PA $(\mathrm{p}=0.011$; $\mathrm{OR}=9.87 ; 95 \% \mathrm{CI}, 1.69$ to 57.61 , logistic regression analysis). Expression of the other MUCl antigens (MUCl/ CORE, MUCl/MY.1E12, MUCl/glycoprotein, and MUCl/ HMFG-1) was not a significant risk factor for the recurrence of PA. No patients showed high expression of MUC2, MUC4, and MUC5AC in either the recurrence or the non-recurrence groups. MUC6 was not a significant risk factor affecting the recurrence of PA (recurrence group, one of nine; nonrecurrence group, four of 40).

Multivariate analysis of factors related to recurrence For multivariate analysis, we used patient's age, patient's sex, tumour size, tumour variant, and high expression of MUCl/ DF3 as the analysed factors because these variables were lower than the cutoff $p$ value that we used $(p<0.20)$ at the univariate level. Table 6 summarises the multivariate analysis for recurrence of PA. High expression of MUC1/DF3 was found to be the only independent significant risk factor to predict the recurrence of PA $(p=0.021 ; O R=20.92 ; 95 \%$ CI, 1.50 to 291.1).

\section{DISCUSSION}

There have been few studies of the clinicopathological risk factors for the recurrence of PA-such as age, stromal ratio, and pseudopodia - that have compared the primary lesions of the recurrence group with those of the non-recurrence group. ${ }^{2-11}$ This is because it is very difficult to collect the primary tumours of recurrent cases: the initial surgery is often carried out in other hospitals or there is a long interval between the initial surgery and recurrence in most patients with PA. In our present study, we found 23 patients who had recurrent PA lesions in our files, but specimens of the primary lesions were available for only nine patients. Previous reports studying primary lesions in the recurrence group revealed the clinicopathological risk factors for the recurrence of $\mathrm{PA}^{2}{ }^{2-11}$ but they did not perform immunohistochemistry. 

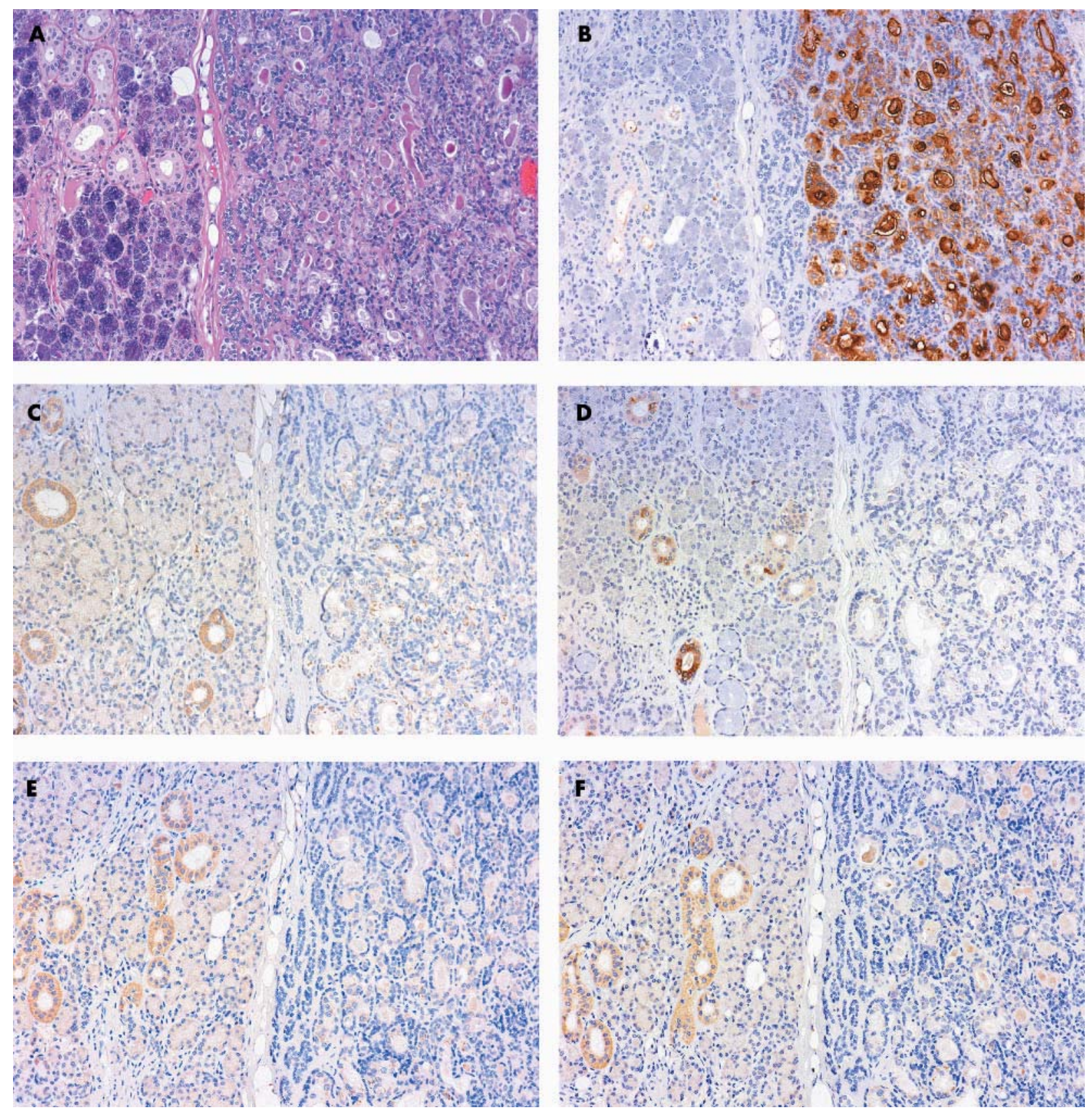

Figure 1 Primary pleomorphic adenoma of the salivary gland in a patient with subsequent recurrence. (A) The tumour cells (right side) were separated from the normal gland (left side) by a thin capsule (haematoxylin and eosin staining). (B) MUC1/DF3 was strongly expressed in the tumour cells. In the normal gland, low expression was seen at the surface of the ductal cells but not in the acinar cells. (C) MUC2, (D) MUC4, (E) MUC5AC, and (F) MUC6 were expressed in the intralobular ducts of the normal salivary gland (left side), but were not expressed in the tumour cells (right side). (D) MUC4 expression in the normal ducts was relatively intense.

In contrast, there have been a few immunohistochemical studies that compared proliferative activity (Ki-67 labelling) or progesterone receptor expression in the secondary recurrent lesions with those in the primary lesions of patients without recurrence. ${ }^{14} 16$ However, they did not evaluate factors in the primary lesions of the recurrence group that might predict a recurrence. Our study is the first to use immunohistochemistry on the primary lesions of patients with a subsequent recurrence. Our present study has shown for the first time that high expression of MUC1/DF3, one of the membrane mucin MUCl antigens, is a significant independent risk factor for the prediction of the recurrence of PA.
In univariate analysis of the clinicopathological factors examined, only tumour size was a significant risk factor for recurrence, and the other risk factors such as younger age ${ }^{9-11}$ and stromal rich variant, ${ }^{11}$ which have been thought to play an important role in the development of recurrence, did not show a higher incidence of recurrence, as reported by others. ${ }^{12}{ }^{13}$ The relation between incomplete surgical removal (for example, tumour spillage, positive surgical resection margin, and capsule rupture during surgery) with the recurrence of PA is also controversial. ${ }^{12}{ }^{4} 12$ Natvig et al found that the recurrence rate after capsule rupture was not significantly different from that seen in other patients, and that there was also no difference in the recurrence rate 

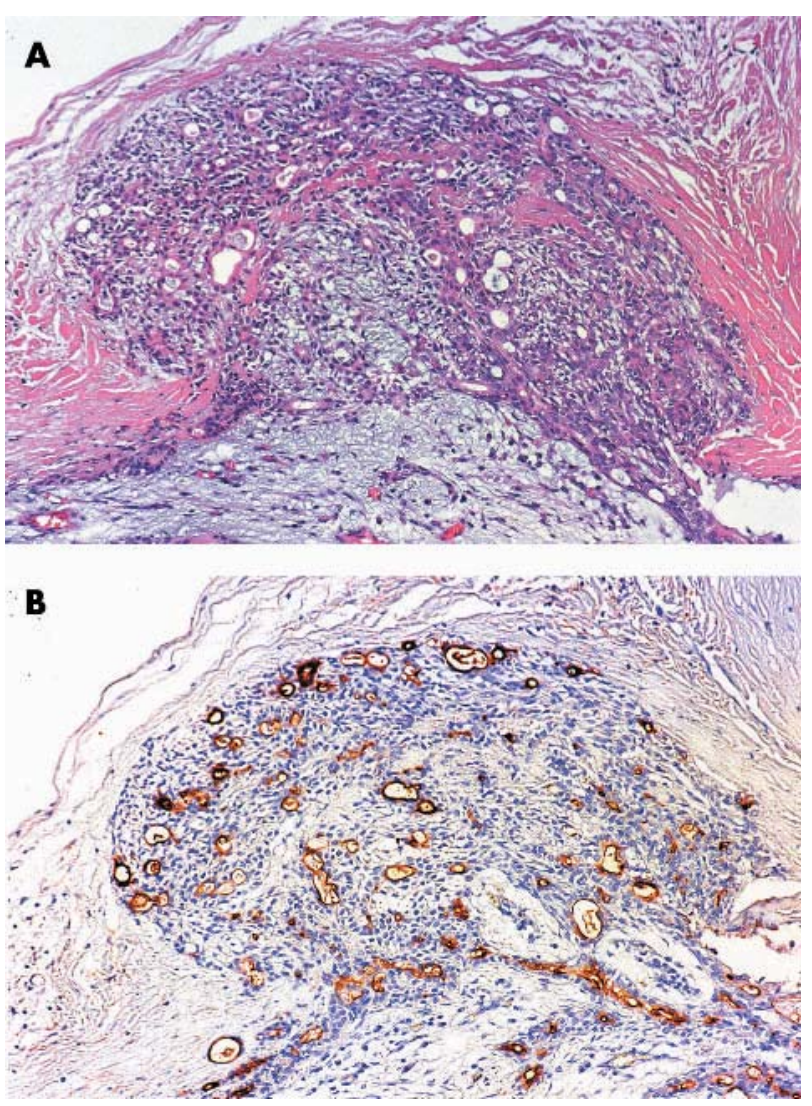

Figure $2 \mathrm{MUCl}$ expression was occasionally seen in the capsular invasion areas. (A) haematoxylin and eosin staining. (B) MUC/DF3 immunohistochemistry. between patients with microscopic positive or negative surgical resection margins. ${ }^{4}$ Incomplete surgical resection was not a significant risk factor for the recurrence of PA in our study also. Consequently, the mechanism of recurrence of PA is unclear, and we suspect that other intrinsic biological factors might play a more important role in the recurrence of PA.

We found that MUC1/DF3 was overexpressed in several cases of PA, and high expression of this antigen was a significant independent factor for predicting the recurrence of PA; that is, the rate of recurrence after initial surgery was significantly higher in patients with high expression of MUCl/DF3 than in those with low expression.

"Our present study has shown for the first time that high expression of $\mathrm{MUCl} / \mathrm{DF} 3$, one of the membrane mucin $\mathrm{MUCl}$ antigens, is a significant independent risk factor for the prediction of the recurrence of pleomorphic adenoma"

In multivariate analysis, only high expression of MUCl/ DF3 was a significant independent risk factor for recurrence. Our previous immunohistochemical studies for mucin expression in various human tumours have shown that MUCl mucin expression is related to invasive tumour growth and poor patient outcome, ${ }^{23-28}$ so that these results agree with our previous findings. MUCl mucin is a transmembrane glycoprotein with an extracellular domain consisting of a variable number of highly conserved tandem repeats of 20 amino acids, a transmembrane domain, and a cytoplasmic tail of 69 amino acids. ${ }^{17}$ Overexpression of MUC1 by cultured cells inhibits their aggregation, possibly because of its large, extended, and rigid structure. ${ }^{40}$ The MUCl expressed in tumours may function as an antiadhesion molecule that inhibits cell-cell adhesion, permitting invasion into surrounding tissues..$^{41}$ Overexpression of MUCl on the

Table 4 Univariate analysis of clinicopathological features

\begin{tabular}{|c|c|c|c|c|c|}
\hline \multirow[b]{2}{*}{ Parameters } & \multirow{2}{*}{$\begin{array}{l}\text { Recurrence } \\
\text { group (\%) }\end{array}$} & \multirow{2}{*}{$\begin{array}{l}\text { Non-recurrence } \\
\text { group (\%) }\end{array}$} & \multicolumn{3}{|c|}{ Univariate analysis } \\
\hline & & & $\overline{\mathrm{OR}}$ & $95 \% \mathrm{Cl}$ & p Value \\
\hline \multicolumn{6}{|l|}{ Age (years) } \\
\hline$<35$ & $4(44)$ & $9(23)$ & 1 & & \\
\hline$>35$ & $5(56)$ & $31(77)$ & 2.76 & 0.61 to 12.47 & 0.19 \\
\hline \multicolumn{6}{|l|}{ Size $(\mathrm{cm})$} \\
\hline$<3.0$ & $3(33)$ & $29(73)$ & 1 & & \\
\hline$>3.0$ & $6(67)^{*}$ & $11(27)$ & 5.27 & 1.12 to 24.85 & 0.035 \\
\hline \multicolumn{6}{|l|}{ Sex } \\
\hline Male & $4(44)$ & $6(15)$ & 1 & & \\
\hline Female & $5(56)$ & $34(85)$ & 4.53 & 0.94 to 21.91 & 0.060 \\
\hline \multicolumn{6}{|l|}{ Site } \\
\hline Parotid & $7(78)$ & $17(42)$ & $4.74 \dagger$ & 0.87 to 25.72 & 0.072 \\
\hline Submandibular & $1(11)$ & $7(17)$ & - & & \\
\hline Palate & $1(11)$ & $13(33)$ & - & & \\
\hline Other oral mucosa & $0(0)$ & $3(7)$ & - & & \\
\hline \multicolumn{6}{|l|}{ Capsular invasion } \\
\hline Negative & $4(44)$ & $16(40)$ & 1 & & \\
\hline Positive & $5(56)$ & $24(60)$ & 1.20 & 0.28 to 5.16 & 0.80 \\
\hline \multicolumn{6}{|l|}{ Tumour variant } \\
\hline Stroma rich & $6(67)$ & $14(35)$ & $3.71 \ddagger$ & 0.80 to 17.17 & 0.096 \\
\hline Intermediate & $2(22)$ & $17(42)$ & - & & \\
\hline Stroma poor & 1 (11) & $9(23)$ & - & & \\
\hline \multicolumn{6}{|l|}{ Margin } \\
\hline Negative & $4(44)$ & $26(65)$ & 1 & & \\
\hline Positive & $5(56)$ & $14(35)$ & 1.49 & 0.34 to 6.44 & 0.60 \\
\hline
\end{tabular}




\begin{tabular}{|c|c|c|c|c|c|}
\hline \multirow[b]{2}{*}{ Antibody } & \multirow{2}{*}{$\begin{array}{l}\text { Recurrence } \\
\text { group }(\%)\end{array}$} & \multirow{2}{*}{$\begin{array}{l}\text { Non-recurrence } \\
\text { group (\%) }\end{array}$} & \multicolumn{3}{|c|}{ Univariate analysis } \\
\hline & & & $\overline{\mathrm{OR}}$ & $95 \% \mathrm{Cl}$ & $p$ Value \\
\hline \multicolumn{6}{|c|}{$\mathrm{MUCl} / \mathrm{CORE}$} \\
\hline LEG & $8(89)$ & $35(88)$ & 1 & & \\
\hline HEG & 1 (11) & $5(12)$ & 1.14 & 0.12 to 11.18 & 0.91 \\
\hline \multicolumn{6}{|c|}{ MUC1/DF3 } \\
\hline LEG & $5(56)$ & $37(92)$ & 1 & & \\
\hline HEG & $4(44)^{*}$ & $3(8)$ & 9.87 & 1.69 to 57.61 & 0.011 \\
\hline \multicolumn{6}{|c|}{ MUC1/MY.1E12 } \\
\hline LEG & $7(78)$ & $34(85)$ & 1 & & \\
\hline HEG & $2(22)$ & $6(15)$ & 0.62 & 0.10 to 3.72 & 0.60 \\
\hline \multicolumn{6}{|c|}{$\mathrm{MUCl} /$ glycoprotein } \\
\hline LEG & $7(78)$ & $34(85)$ & 1 & & \\
\hline HEG & $2(22)$ & $6(15)$ & 0.62 & 0.10 to 3.72 & 0.60 \\
\hline \multicolumn{6}{|c|}{ MUC1/HMFG-1 } \\
\hline LEG & $8(89)$ & $40(100)$ & & & \\
\hline HEG & $1(11)$ & $0(0)$ & - & - & ND \\
\hline \multicolumn{6}{|l|}{ MUC2 } \\
\hline LEG & $9(100)$ & $40(100)$ & & & \\
\hline HEG & $0(0)$ & $0(0)$ & - & - & ND \\
\hline \multicolumn{6}{|l|}{ MUC4 } \\
\hline LEG & $9(100)$ & $40(100)$ & & & \\
\hline HEG & $0(0)$ & $0(0)$ & - & - & ND \\
\hline \multicolumn{6}{|l|}{ MUC5AC } \\
\hline LEG & $9(100)$ & $40(100)$ & & & \\
\hline HEG & $0(0)$ & $0(0)$ & - & - & ND \\
\hline \multicolumn{6}{|l|}{ MUC6 } \\
\hline LEG & $8(89)$ & $36(90)$ & 1 & & \\
\hline HEG & 1 (11) & $4(10)$ & 0.89 & 0.09 to 9.06 & 0.92 \\
\hline \multicolumn{6}{|c|}{$\begin{array}{l}\text { *In Fisher's exact test, the rate of high expression of } \mathrm{MUCl} / \mathrm{DF} 3 \text { in the primary lesions of the recurrence group was } \\
\text { significantly higher than that of the non-recurrence group }(\mathrm{p}=0.016) \text {. } \\
\mathrm{Cl} \text {, confidence interval; } \mathrm{HEG} \text {, the high expression group composed of the ++ cases (more than } 30 \% \text { of the } \\
\text { neoplastic cells stained); } \mathrm{EEG} \text {, the low expression group composed of the - and + cases (less than } 30 \% \text { of } \\
\text { neoplastic cells stained): ND not determined. OR odds ratio. }\end{array}$} \\
\hline
\end{tabular}

membrane of cultured cells may also inhibit interaction between cytotoxic lymphocytes and tumour cells. ${ }^{42}$ Cells with high amounts of MUCl have reduced interaction between integrins and the extracellular matrix. ${ }^{43} \mathrm{~A}$ recent experimental study by Suwa et al showed that cultured gastric cancer cells acquire increased motility and invasive abilities when they are transfected with the MUCl gene. ${ }^{44} \mathrm{~A}$ mechanism for the inhibition of E-cadherin mediated cellcell adhesion by MUCl has also been reported..$^{45}$ These experimental data may explain the relation between MUC1 mucin expression and the progression of malignant tumours. Our present study showed that MUCl/DF3 expression is also related to tumour recurrence in $\mathrm{PA}$, which is originally a benign tumour.

Table 6 Multivariate analysis of recurrence of PA

\begin{tabular}{llll}
\hline Factors & OR & $95 \% \mathrm{Cl}$ & $\mathrm{p}$ Value \\
\hline $\begin{array}{l}\text { Age (years) } \\
\quad 35\end{array}$ & 1 & & \\
$\quad<35$ & 1.48 & 0.21 to 10.55 & 0.70 \\
$\begin{array}{l}\text { Size }(\mathrm{cm}) \\
\quad<3.0\end{array}$ & 1 & & \\
$\quad>3.0$ & 4.80 & 0.68 to 33.95 & 0.12 \\
$\begin{array}{l}\text { Sex } \\
\quad \text { Female }\end{array}$ & 1 & & \\
$\quad \begin{array}{l}\text { Male } \\
\text { Tumour variant } \\
\quad \text { Intermediate or stroma poor }\end{array}$ & 1 & & \\
$\quad \begin{array}{l}\text { Stroma rich } \\
\text { MUC1/DF3 } \\
\quad \text { LEG }\end{array}$ & 4.58 & 0.42 to 30.71 & 0.24 \\
$\quad$ HEG & 1 & & \\
\hline
\end{tabular}

$\mathrm{Cl}$, confidence interval; $\mathrm{HEG}$, the high expression group composed of the ++ cases (more than $30 \%$ of the neoplastic cells stained); LEG, the low expression group composed of the - and + cases (less than $30 \%$ of neoplastic cells stained); OR, odds ratio.
Among the various forms of MUCl mucins examined, only MUCl/DF3 expression was related to the recurrence of PA, and this difference might be related to the different epitopes recognised by the various antibodies. Tumour cells expressing sialomucin have been shown to be less sensitive to cytolysis by human activated killer lymphocytes ${ }^{46-49}$ and high amounts of cell surface sialomucin may be related to escape from immunological attack. ${ }^{4750}$ MUCl/MY.1E12 is a sialylated MUCl. ${ }^{36}$ MUCl/glycoprotein also seems to be a sialylated MUCl according to the results of the sialidase digestion test in our previous study. ${ }^{25} \mathrm{~A}$ recent study also reported that the MUCl/glycoprotein epitope detected by MAb NCL/MUC-1 (clone Ma695) involves sialic acid. ${ }^{37}$ HMFG-1 detects fully glycosylated MUCl mucin, and its binding is particularly affected by sialic acid. ${ }^{38}$ However, the high expression of MUCl/MY.1E12, MUCl/glycoprotein, and HMFG-l was not related to the recurrence of PA in our present study. The MUC1/DF3 epitope has been thought to involve TRPAPG with a sialylated sugar chain. ${ }^{35}$ However, a recent study reported that the MUCl/DF3 epitope does not contain carbohydrate, but core peptide only (APDTRPAP). ${ }^{34}$ The MUCl/CORE epitope (detected by clone Ma552) is also a

\section{Take home messages}

- $\mathrm{MUC1}$ /DF3 expression in pleomorphic adenoma (PA) is a useful marker to predict its recurrence

- Patients with PA who are positive for MUC1/DF3 expression should be followed up carefully

- Prediction of the risk of recurrence by MUC1/DF3 staining in biopsy material may be useful for selecting the surgical procedure 
core peptide only (GVTSAPDTRPAP), but high expression of MUCl/CORE was not related to the recurrence of PA. The difference between the MUCl/DF3 epitope and the MUCl/ CORE, MUCl/MY.1E12, MUCl/glycoprotein, and MUCl/ HMFG-1 epitopes may be responsible for the differences in their association with recurrence of PA. The role of the MUCl/DF3 epitope would be an interesting future area of study.

In conclusion, we report for the first time that the expression of MUC1/DF3 in PA is a useful marker to predict the recurrence of PA. Patients with PA showing positive MUCl/DF3 expression should be followed up carefully. Prediction of the risk of recurrence by MUCl/DF3 staining in biopsy material may be useful for selecting the surgical procedure.

\section{ACKNOWLEDGEMENTS}

The authors thank Mr Y Atsuji, Ms Y Arimura, and Ms Y Nishimura for their excellent technical assistance. Supported by Grant-in-Aid 13220016 to S Yonezawa from the Ministry of Education, Science, Sports, Culture and Technology, Japan, and by USPHS grant CA 78590 from the National Institutes of Health to SK Batra.

\section{Authors' affiliations}

T Hamada, K Sugihara, Department of Maxillofacial Diagnostic and Surgical Science, Field of Oral and Maxillofacial Rehabilitation Kagoshima University Graduate School of Medicine and Dental Sciences, 8-35-1 Sakuragaoka, Kagoshima 890-8544, Japan M Goto, $\mathbf{S}$ Yonezawa, Department of Human Pathology, Field of Oncology, Kagoshima University Graduate School of Medical and Dental Sciences

S Matsukita, K Sueyoshi, Department of Pathology, Kagoshima City Hospital, Kagoshima, Japan

S Kitajima, Department of Pathology, Kagoshima University Hospital, Kagoshima, Japan

S K Batra, Departments of Biochemistry and Molecular Biology, Eppley Institute for Research in Cancer and Allied Diseases, University of Nebraska Medical Center, Omaha, USA

T Irimura, Laboratory of Cancer Biology and Molecular Immunology, Graduate School of Pharmaceutical Sciences, The University of Tokyo, Japan

\section{REFERENCES}

1 Buchman C, Stringer SP, Mendenhall WM, et al. Pleomorphic adenoma: effect of tumor spill and inadequate resection on tumor recurrence. Laryngoscope 1994; 104:1231-4.

2 Henriksson G, Westrin KM, Carlsoo B, et al. Recurrent primary pleomorphic adenomas of salivary gland origin: intrasurgical rupture, histopathologic features, and pseudopodia. Cancer 1998;82:617-20.

3 McGurk M, Renehan A, Gleave EN, et al. Clinical significance of the tumour capsule in the treatment of parotid pleomorphic adenomas. Br J Surg 1996;83:1747-9

4 Natvig K, Soberg R. Relationship of intraoperative rupture of pleomorphic adenomas to recurrence: an 11-25 year follow-up study. Head Neck 1994; 16:213-17.

5 Phillips PP, Olsen KD. Recurrent pleomorphic adenoma of the parotid gland: report of 126 cases and a review of the literature. Ann Otol Rhinol Laryngol 1995; 104:100-4.

6 Glas AS, Vermey A, Hollema H, et al. Surgical treatment of recurrent pleomorphic adenoma of the parotid gland: a clinical analysis of 52 patients. Head Neck $2001 ; 23: 311-16$.

7 Leverstein $\mathrm{H}$, Tiwari RM, Snow GB, et al. The surgical management of recurrent or residual pleomorphic adenomas of the parotid gland. Analysis and results in 40 patients. Eur Arch Otorhinolaryngol 1997;254:313-17.

8 Becelli R, Perugini M, Mastellone P, et al. Surgical treatment of recurrences of pleomorphic adenoma of the parotid gland. J Exp Clin Cancer Res 2001;20:487-9.

9 Maran AG, Mackenzie IJ, Stanley RE. Recurrent pleomorphic adenomas of the parotid gland. Arch Otolaryngol 1984;110:167-71.

10 McGregor AD, Burgoyne M, Tan KC. Recurrent pleomorphic salivary adenoma - the relevance of age at first presentation. $\mathrm{Br} J$ Plast Surg 1988:41:177-81.

11 Chilla R, Schneider K, Droese M. [Recurrence tendency and malignant transformation of pleomorphic adenomas.] HNO 1986;34:467-9.

12 Witt RL. The significance of the margin in parotid surgery for pleomorphic adenoma. Laryngoscope 2002;112:2141-54.

13 Laccourreye $\mathbf{H}$, Laccourreye $\mathrm{O}$, Cauchois $\mathrm{R}$, et al. Total conservative parotidectomy for primary benign pleomorphic adenoma of the parotid gland: a 25-year experience with 229 patients. Laryngoscope 1994: 104:1487-94.

14 Glas AS, Hollema H, Nap RE, et al. Expression of estrogen receptor progesterone receptor, and insulin-like growth factor receptor-1 and of MIB-1 in patients with recurrent pleomorphic adenoma of the parotid gland. Cancer 2002;94:2211-16.

15 Ohtake S, Cheng J, Ida $\mathrm{H}$, et al. Precancerous foci in pleomorphic adenoma of the salivary gland: recognition of focal carcinoma and atypical tumor cells by P53 immunohistochemistry. J Oral Pathol Med 2002;31:590-7.

16 Bankamp DG, Bierhoff E. [Proliferative activity in recurrent and nonrecurrent pleomorphic adenoma of the salivary glands.] Laryngorhinootologie 1999;78:77-80

17 Dekker J, Rossen JW, Buller HA, et al. The MUC family: an obituary. Trends Biochem Sci 2002;27:126-31.

18 Gum JR Jr, Crawley SC, Hicks JW, et al. MUC17, a novel membrane-tethered mucin. Biochem Biophys Res Commun 2002;291:466-75.

19 Chang SK, Dohrman AF, Basbaum CB, et al. Localization of mucin (MUC2 and MUC3) messenger RNA and peptide expression in human normal intestine and colon cancer. Gastroenterology 1994;107:28-36.

20 Porchet N, Nguyen VC, Dufosse J, et al. Molecular cloning and chromosoma localization of a novel human tracheo-bronchial mucin cDNA containing tandemly repeated sequences of 48 base pairs. Biochem Biophys Res Commun 1991;175:414-22.

21 Carraway KL, Ramsauer VP, Haq B, et al. Cell signaling through membrane mucins. Bioessays 2003;25:66-71.

22 De Bolos C, Garrido M, Real FX. MUC6 apomucin shows a distinct normal tissue distribution that correlates with Lewis antigen expression in the human stomach. Gastroenterology 1995; 109:723-34.

23 Osako M, Yonezawa S, Siddiki B, et al. Immunohistochemical study of mucin carbohydrates and core proteins in human pancreatic tumors. Cancer 1993;71:2191-9.

24 Kitamura H, Yonezawa S, Tanaka S, et al. Expression of mucin carbohydrates and core proteins in carcinomas of the ampulla of Vater: their relationship to prognosis. Jpn J Cancer Res 1996;87:631-40.

25 Higashi M, Yonezawa S, Ho JJ, et al. Expression of MUC1 and MUC2 mucin antigens in intrahepatic bile duct tumors: its relationship with a new morphological classification of cholangiocarcinoma. Hepatology 1999:30:1347-55

26 Tamada S, Goto $M$, Nomoto $M$, et al. Expression of $M U C 1$ and MUC2 mucin in extrahepatic bile duct carcinomas: its relationship with tumor progression and prognosis. Pathol Int 2002:52:713-23.

27 Utsunomiya T, Yonezawa S, Sakamoto $\mathrm{H}$, et al. Expression of $\mathrm{MUCl}$ and MUC2 mucins in gastric carcinomas: its relationship with the prognosis of the patients. Clin Cancer Res 1998;4:2605-14.

28 Yonezawa S, Sato E. Expression of mucin antigens in human cancers and its relationship with malignancy potential. Pathol Int 1997:47:813-30.

29 Yonezawa S, Sueyoshi K, Nomoto M, et al. MUC2 gene expression is found in noninvasive tumors but not in invasive tumors of the pancreas and liver: its close relationship with prognosis of the patients. Hum Pathol 1997;28:344-52

30 Liu B, Lague JR, Nunes DP, et al. Expression of membrane-associated mucin MUC1 and MUC4 in major human salivary glands. J Histochem Cytochem 2002;50:81 1-20.

31 Swartz MJ, Batra SK, Varshney GC, et al. MUC4 expression increases progressively in pancreatic intraepithelial neoplasia. Am J Clin Pathol 2002:117.791-6.

32 Horinouchi M, Nagata K, Nakamura A, et al. Expression of different glycoforms of membrane mucin (MUC1) and secretory mucin (MUC2, MUC5AC and MUC6) in pancreatic neoplasms. Acta Histochem Cytochem 2003:36:443-53.

33 Matsukita S, Nomoto $M$, Kitaijma $S$, et al. Expression of mucins $(\mathrm{MUCl}$, MUC2, MUC5AC and MUC6) in mucinous carcinoma of the breast: comparison with invasive ductal carcinoma. Histopathology 2003;42:26-36.

34 Price MR, Rye PD, Petrakou E, et al. Proceedings of the International Society for Oncodevelopmental Biology and Medicine (ISOBM) TD-4 international workshop on monoclonal antibodies against MUC1. San Diego, California, November 17-23, 1996. Tumour Biol 1998;19(suppl 1):1-152.

35 Siddiqui J, Abe $M$, Hayes $D$, et al. Isolation and sequencing of a cDNA coding for the human DF3 breast carcinoma-associated antigen. Proc Natl Acad Sci U S A 1988:85:2320-3.

36 Takeuchi H, Kato K, Denda-Nagai K, et al. The epitope recognized by the unique anti-MUC1 monoclonal antibody MY.1E12 involves sialyl alpha 2 3galactosyl beta 1-3N-acetylgalactosaminide linked to a distinct threonine residue in the MUC1 tandem repeat. J Immunol Methods 2002;270:199-209.

37 Cao Y, Karsten U. Binding patterns of 51 monoclonal antibodies to peptide and carbohydrate epitopes of the epithelial mucin (MUC1) on tissue sections of adenolymphomas of the parotid (Warthin's tumours): role of epitope masking by glycans. Histochem Cell Biol 2001;115:349-56.

38 Burchell J, Taylor-Papadimitriou J. Effect of modification of carbohydrate side chains on the reactivity of antibodies with core-protein epitopes of the MUC1 gene product. Epithelial Cell Biol 1993;2:155-62.

39 Park HU, Kim JW, Kim GE, et al. Aberrant expression of MUC3 and MUC4 membrane-associated mucins and sialyl lex antigen in pancreatic intraepithelial neoplasia. Pancreas 2003;26:E48-54

40 Ligtenberg MJ, Buijs F, Vos HL, et al. Suppression of cellular aggregation by high levels of episialin. Cancer Res 1992;52:2318-24.

41 Makiguchi $Y$, Hinoda Y, Imai K. Effect of MUC1 mucin, an anti-adhesion molecule, on tumor cell growth. Jpn J Cancer Res 1996:87:505-11.

42 van de Wiel-van Kemenade E, Ligtenberg MJ, de Boer AJ, et al. Episialin (MUC1) inhibits cytotoxic lymphocyte-target cell interaction. J Immunol 1993;151:767-76. 
43 Wesseling J, van der Valk SW, Vos HL, et al. Episialin (MUC1) overexpression inhibits integrin-mediated cell adhesion to extracellular matrix components. J Cell Biol 1995; 129:255-65.

44 Suwa T, Hinoda Y, Makiguchi Y, et al. Increased invasiveness of $M U C 1$ and cDNA-transfected human gastric cancer MKN74 cells. Int J Cancer 1998; 76:377-82.

45 Wesseling J, van der Valk SW, Hilkens J. A mechanism for inhibition of Ecadherin-mediated cell-cell adhesion by the membrane-associated mucin episialin/MUC1. Mol Biol Cell 1996;7:565-77.

46 Van Rinsum J, Smets LA, Van Rooy H, et al. Specific inhibition of human natural killer cell-mediated cytotoxicity by sialic acid and sialooligosaccharides. Int J Cancer 1986;38:915-22.
47 Irimura T, Mclsaac AM, Carlson DA, et al. Soluble factor in normal tissues that stimulates high-molecular-weight sialoglycoprotein production by human colon carcinoma cells. Cancer Res 1990;50:3331-8.

48 Moriarty J, Skelly CM, Bharathan S, et al. Sialomucin and lytic susceptibility of rat mammary tumor ascites cells. Cancer Res 1990;50:6800-5

49 Ogata S, Maimonis PJ, Itzkowitz SH. Mucins bearing the cancer-associated sialosyl-Tn antigen mediate inhibition of natural killer cell cytotoxicity. Cancer Res 1992;52:4741-6.

50 Irimura T, Nakamori S, Matsushita Y, et al. Colorectal cancer metastasis determined by carbohydrate-mediated cell adhesion: role of sialyl-LeX antigens. Semin Cancer Biol 1993;4:319-24.

\section{Making Health Care Safer 2004}

21-22 October 2004

Royal College of Physicians, London

A two day conference for all professionals dedicated to providing safer health care for all.

Register now! Early booking discount available.

See website for details: www.quality.bmipg.com 